\title{
Insights into the molecular etiology of exercise-induced inflammation: opportunities for optimizing performance
}

This article was published in the following Dove Press journal:

Journal of Inflammation Research

21 October 2016

Number of times this article has been viewed

\author{
Ioannis G Fatouros \\ Athanasios $Z$ Jamurtas \\ School of Physical Education and \\ Sport Sciences, University of Thessaly, \\ Karies, Trikala, Greece
}

\begin{abstract}
The study of exercise-induced muscle damage (EIMD) is of paramount importance not only because it affects athletic performance but also because it is an excellent model to study the mechanisms governing muscle cachexia under various clinical conditions. Although, a large number of studies have investigated EIMD and its associated inflammatory response, several aspects of skeletal muscles responses remain unclear. In the first section of this article, the mechanisms of EIMD are reviewed in an attempt to follow the events that result in functional and structural alterations of skeletal muscle. In the second section, the inflammatory response associated with EIMD is presented with emphasis in leukocyte accumulation through mechanisms that are largely coordinated by pro- and anti-inflammatory cytokines released either by injured muscle itself or other cells. The practical applications of EIMD and the subsequent inflammatory response are discussed with respect to athletic performance. Specifically, the mechanisms leading to performance deterioration and development of muscle soreness are discussed. Emphasis is given to the factors affecting individual responses to EIMD and the resulting interindividual variability to this phenomenon.
\end{abstract}

Keywords: muscle damage, exercise, aseptic inflammation, recovery, immune system, redox status

\section{Introduction}

Skeletal muscle injury may result from toxin injection, crushing, freezing, and mechanical disruption induced by forceful stretches of muscle fibers. Skeletal muscle fiber damage may also result from intense, unaccustomed, extreme (i.e., ultra-endurance events such as marathon running, triathlon, etc.) and/or eccentric types of exercises that are characterized by forceful lengthening contractions during which muscle fibers are overstretched. ${ }^{1}$

According to the model of Proske and Allen, ${ }^{2}$ within stretched fibers, some sarcomeres may be more resilient than others resulting in greater absorption of the stretch by the weaker sarcomeres which, depending on the magnitude of the stretch, become more vulnerable as the overlap between myosin and actin filaments is minimized toward the end of the stretch. Following numerous eccentric stretches, more and more of the weaker sarcomeres are gradually overstretched, and as fiber stretching continues, the more resilient sarcomeres become overstretched. Since myofilaments of these sarcomeres may not return to their original overlapping state during the relaxation phase of the muscle, a mechanical disruption of these sarcomeres develops which is eventually transmitted to neighboring areas in muscle vicinity resulting in subcellular
Correspondence: loannis G Fatouros School of Physical Education and Sport Science, University of Thessaly, Karies, Trikala 42100, Greece

Tel +302431047047

$\mathrm{Fax}+302431047042$

Email ifatouros@pe.uth.gr 
damage, that is, a collapse of membrane surrounding the sarcoplasmic reticulum, transverse tubules, and the muscle fibers themselves. This series of events compromises the process of excitation-contraction coupling in damaged sarcomeres and results in the release of calcium ions from sarcoplasmic reticulum into the cytoplasm where they stimulate proteolytic enzymes that promote further muscle fiber degradation. ${ }^{1,2}$ During this first phase, aseptic exerciseinduced muscle damage (EIMD) leads to the onset of an inflammatory response associated with the activation of leukocytes, muscle edema, deterioration of muscle function, delayed-onset of muscle soreness (DOMS), increased release of muscle proteins into the interstitial space, and circulation and a rise in muscle temperature. ${ }^{3}$

Even after an extensive injury, skeletal muscle demonstrates an extraordinary ability for healing. Consequently, a regeneration or healing phase follows the first inflammatory phase. ${ }^{4}$ Muscle regeneration is related to the activation of a set of mononucleated cells, known as satellite cells, which subsequently proliferate, differentiate, and enter the damaged myofibers to synthesize new fibers or contribute to the healing of other fibers with a less severe damage. ${ }^{5}$ This phase is characterized by a marked rise of muscle protein synthesis. ${ }^{4}$ The inflammatory and the regeneration phases are operationally interconnected, and the disturbance of the former may hamper the later. ${ }^{6}$ Evidence suggests that suppression of the inflammatory phase may lead to an attenuated overcompensation or healing during the regeneration phase. ${ }^{7}$ The scope of the present article is to review the first inflammatory phase and disclose important implications for exercise training and overall athletic performance. The mechanisms underlying EIMD are presented in the first part of this review. The second part describes the initiation and propagation of local and systemic inflammatory response. Finally, the third part presents the changes in skeletal muscle performance during the inflammatory response and discusses important implications for sports performance.

\section{Mechanisms and consequences}

EIMD is associated with muscle soreness or discomfort and a marked decline of muscle strength during the first 12-72 $\mathrm{h}$ postexercise depending on the magnitude of the muscle-damaging exercise, and as stated earlier, it is related to the disruption of subcellular structures. ${ }^{8}$ Although this phenomenon was described as early as the first part of the 20 th century, 9,10 the mechanisms underlying EIMD are not entirely understood. Despite that isometric (static work, length of the muscle remains unchanged) and concentric (length of the muscle decreases) muscle contractions are able to elevate skeletal muscle damage markers, the vast majority of published studies support the notion that eccentric work is primarily associated with EIMD. ${ }^{1,3,4,8}$ Eccentric (lengthening) work, either in their isolated form on an isokinetic dynamometer or as a part of the stretch-shortening cycle during downhill running, is used experimentally to study EIMD. In fact, eccentric EIMD is thought to be the basis for the increase of skeletal muscle mass (hypertrophy) seen with exercise training, especially resistance exercise training, suggesting that muscle micro-trauma induced by mechanical stress of acute exercise is a prerequisite for its subsequent growth during the adaptation phase. ${ }^{11,12}$ Moreover, Givli ${ }^{12}$ suggested that EIMD may also be utilized to develop safer and more effective training and recovery protocols based on a personalized approach.

Study of EIMD aids to understand the mechanisms governing muscle degeneration and regeneration, so that findings may be extrapolated to various clinical conditions that demonstrate deviations in these mechanisms such as in dystrophies, inflammaging, cancer, and so on. For example, muscular dystrophies are characterized by extensive skeletal muscle degeneration due to the lack of dystrophin, calcium toxicity, free radical generation, activation of proteolytic enzymes, degradation of muscle proteins, and finally loss of muscle function and patient's physical independence. ${ }^{13}$ Understanding the molecular mechanisms linking muscle damage with inflammatory cascade and proteolysis using the EIMD model to induce mechanical strain to the cytoskeleton of the muscle could help toward the development of potential treatments for the clinical symptoms associated with this disease. ${ }^{14,15}$ During the last few years, a number of pharmacological agents and/or nutritional supplements have been tested in this direction using the EIMD model. ${ }^{16-18}$ Rheumatoid arthritis (RA) represents another example. RA demonstrates an intense inflammatory response through the production of the inflammatory cytokines at the site of the disease (i.e., joints) affecting distant tissues and play a significant role in skeletal muscle wasting. ${ }^{19}$ Furthermore, oxidative stress is frequently reported in patients with RA since cells present in inflamed joints (e.g., macrophages, neutrophils, and lymphocytes) have the ability to produce free radicals. ${ }^{20}$ Therefore, finding ways to manipulate the inflammatory responses and modulate the redox response following EIMD could give insights on cellular mechanisms leading to muscle cachexia and how to confront clinical conditions like RA and potentially others. 
DOMS and strength loss during EIMD were originally attributed to subcellular disruption of skeletal muscle fibers. ${ }^{10,12}$ This notion was further supported by the indirect evidence of increased concentration of muscle proteins into the circulation in response to EIMD, suggesting a potential leakage of intracellular content due to damage of muscle fiber membrane. ${ }^{12,21,22}$ This theory was further supported by marked sarcomeric distortions (e.g., Z-line streaming) identified by electron microscopy following EIMD in both human and animal studies ${ }^{12,23,24}$ or infiltration of extracellular dyes into the muscle in animal studies. ${ }^{16,25}$ Damage of muscle fiber membrane also causes influx of extracellular substances (e.g., albumin and fibronectin). ${ }^{12,26,27}$ Increased membrane permeability has been linked to the stimulation of sodium and calcium channels in response to repetitive stretching of muscle fibers by lengthening contractions. ${ }^{28,29}$ Nevertheless, a large variation exists in the manifestations of the magnitude of EIMD induced by eccentric exercise protocols ranging from extensive local or systemic inflammatory responses and myofiber trauma ${ }^{7,12,30}$ to less pronounced injury in humans ${ }^{31}$ probably due to large variations in muscles tested as well as exercise protocols used. Moreover, protocols using electrical stimulation on animals to simulate eccentric contractions, although useful to study molecular mechanisms underlying EIMD, may not be physiologically relevant to that produced by humans..$^{32}$ Electron microscopy revealed that EIMD is characterized by extensive fiber necrosis, Z-line streaming at sarcomere level for as long as 1-3 days following eccentric exercise depending on the magnitude of the exercise stimulus, ${ }^{12,23,24,30,33}$ and deterioration of a significant structural (e.g., desmin and dystrophin) and myofibrillar proteins (e.g., myosin), suggesting an increased rate of degradation..$^{32,34-36}$ Necrotic parts of injured myofibers appear histochemically as inflated and orbicular. ${ }^{37}$ Although others argue that eccentric exercise does not cause necrosis, ${ }^{38}$ myofiber necrosis may be accompanied by macrophage infiltration, especially at the perimysium and endomesium, through toll-like receptors indicating an abrupt mobilization of the immune system during the first hours postexercise..$^{30,39,40}$ Interestingly, damaged myofibers also demonstrate the aggregation of satellite cellderived myoblasts..$^{30,38,41-43}$ These findings suggest that DOMS and strength loss are primarily related to this disruption of contractile and structural proteins located in sarcomeres. However, Yu et a $1^{44}$ suggested that these structural deformations of muscle fibers do not indicate muscle damage but rather a regeneration process suggestive of an adaptation at cellular level. Animal models seem to demonstrate a greater rate of subcellular derangement than human models..$^{44,45}$
Muscles of the upper limbs seem to be more susceptible to EIMD probably due to their smaller muscle mass and utilization in daily activities. ${ }^{46,47}$

Extracellular matrix, mainly connective tissue, is affected by EIMD as well. Muscle fibers are mechanically connected with extracellular matrix through a complex organization of membrane-bound proteins (i.e., integrins, dystroglycans, and proteoglycans) that enable mechanical transmission among muscle fibers and fascicles. ${ }^{48}$ Histological data indicate that EIMD widens parts of the perimysium and endomysium with connective tissue dissociated from muscle fibers into a more expanded interstitium. ${ }^{27}$ These findings are coupled with others showing increased and prolonged collagen turnover indicative of a remodeling of extracellular matrix in response to its damage by exercise. ${ }^{49,50}$ However, extracellular matrix contains not only collagen fibers but also endothelial and pericyte cells, immune cells, stromal cells such as fibroblasts, nerve cells, and satellite cells that all combine to produce a physiological response, that is, muscle contraction. It is uncertain how all these cells are affected by EIMD and whether their potential damage or remodeling affects skeletal muscle fiber homeostasis. For example, intramuscular mechanical pressure during EIMD is transferred through the extracellular matrix inducing an early release of growth factors from fibroblasts that result in the activation of adjacent satellite cell populations via selective intracellular signaling pathways which may promote muscle healing. ${ }^{51,52}$ Vascular cells such as pericytes are also involved in EIMD by activating nuclear factor-kappa $\mathrm{B}(\mathrm{NF}-\kappa \mathrm{B})$ signaling which is implicated in immune cell mobilization and satellite cell proliferation. ${ }^{7,53,54}$ However, it must be mentioned that NF- $\kappa B$ pathway mediates the upregulation of the activity of the ubiquitin-proteosome system (UPS) by proinflammatory cytokines (i.e., tumor necrosis factor-alpha $[\mathrm{TNF}-\alpha]$ and interleukin-6 [IL-6]) thereby contributing to protein degradation of skeletal muscle proteins and overall EIMD. ${ }^{55}$ It is unclear whether the activation of UPS contributes or exacerbates EIMD or it represents a protective mechanism that clears damaged protein molecules and as such accelerates the inflammatory cascade and the subsequent healing. The involvement of the NF-KB-UPS pathway in EIMD constitutes a valuable experimental model to study skeletal muscle atrophy in conditions such as sepsis and cachexia induced by cancer and other clinical conditions. Therefore, it seems that extracellular matrix may be actively involved during EIMD and may affect muscle fiber healing, a perspective that needs to be addressed by future investigations. 
As mentioned earlier, EIMD is associated with prolonged deterioration of muscle strength, DOMS, edema, increased temperature, and leakage of muscle proteins into the circulation. ${ }^{56,57}$ Prolonged (1-14 days) muscle strength reduction $(10 \%-70 \%)$ is considered as one of the most valid markers of EIMD since among all markers they exhibit the highest correlation with histological evidence of muscle disruption. ${ }^{8,56,58,59}$ Recovery kinetics of muscle strength depend on genetics, the type of exercise, muscle group(s) involved, intensity, volume, and novelty of exercise. ${ }^{28}$ Strength loss is attributed to the socalled half-sarcomere nonuniformity, which states that most of finer length adjustment is accommodated by the weakest half-sarcomeres, which become weaker as muscle lengthening progresses and advances beyond the point of myofilament overlap and ultimately microtears develop. ${ }^{2,60}$ Repeated stretching further increases traumatized sarcomeres, and injury of muscle fibers is exacerbated causing membrane disruption and perforation of channels stimulated by mechanical stretch. ${ }^{2,60}$ Damage of junctophilins, that is, proteins connecting t-tubules with the membrane of sarcoplasmic reticulum mediating the communication between the calcium release channel and the dihydropyridine receptor, may also contribute to strength losses due to uncoupling of the excitation-contraction mechanism. ${ }^{61,62}$ This cascade of events induces a collapse of the excitation-contraction coupling mechanism and calcium kinetics from sarcoplasmic reticulum resulting in strength reduction. ${ }^{63,64}$ This mechanism accounts for $\sim 75 \%$ of early (up to $72 \mathrm{~h}$ ) muscle strength deterioration with injury of other force-generating and transmitting structures accounting for the remaining 25\%. ${ }^{65}$ Damage of junctophilin proteins results in the rise of intracellular calcium which then stimulates calcium-activated proteolytic enzymes (i.e., calpains) that further degrade contractile and other muscle proteins, ${ }^{66}$ a mechanism also shown by experimentation with dystrophic mdx mice with an inherent stimulation of calcium channels. ${ }^{67}$ In fact, removal of calcium from muscle's environment or inhibition of calcium channels with pharmacological agents restores or attenuates strength decline following eccentric work in some studies with mdx mice ${ }^{68,69}$ but not in healthy muscle. ${ }^{70}$ According to Warren et al, ${ }^{65}$ degradation of contractile proteins may further contribute to strength loss during prolonged ( $>72 \mathrm{~h}$ ) muscle injury. Although evidence implicates various other structural and contractile proteins, such as $\alpha$-actinin- 3 , in strength loss following damaging exercise, ${ }^{71,72}$ more research is needed in order to understand the mechanical aspect of their contribution.

DOMS usually peaks 1-2 days postexercise and recovers to baseline levels after 4-7 days. ${ }^{73,74}$ In contrast to muscle strength loss, DOMS demonstrates a moderate to low correlation with histological evidence of EIMD probably due to a significant variability of subjects. ${ }^{73}$ DOMS is attributed to muscle fiber disruption, disturbance of calcium homeostasis, and firing of IV nerves in response to various inflammatory by-products. ${ }^{75,76}$ In fact, synthesis and release of inflammatory agents (e.g., bradykinin, prostaglandins, histamine, and nerve growth factor) by proinflammatory cells (e.g., immune cells) postexercise may actually trigger selective pain receptors and produce soreness. ${ }^{77,78}$ Available evidence suggests that nitric oxide (NO) produced by muscle NO synthase may also stimulate nociceptors of $\mathrm{C}$-fibers, thereby inducing a pain sensation. ${ }^{76}$ Generation of free radicals by the nicotinamide adenine dinucleotide phosphate (NADPH) oxidase mechanism of the immune cells may also contribute to the damage of injured and noninjured muscle fibers and the onset of DOMS, a phenomenon also known as respiratory burst-induced secondary damage. ${ }^{1,8}$

Allen et $\mathrm{al}^{28}$ suggested that skeletal muscle responses to EIMD follow a continuum with the type of eccentric muscle activation, genetic variability, muscle group engaged, and overload characteristics (intensity, volume, and degree of novelty) being the main determinants of the type of adaptations induced. EIMD is more severe when electrical stimulation is utilized to induce eccentric contraction (as compared to voluntary eccentric activation), genetic background is optimal (high vs. low respondents), and intensity, volume, and novelty are of sufficient magnitude. ${ }^{28}$ When EIMD is less severe, there is an increased likelihood for positive adaptations, whereas in more severe EIMD, an intense disruption of muscle fibers occurs and an augmented inflammatory response develops. ${ }^{28}$ In more extreme cases, a maladaptation occurs resulting in musculoskeletal injuries (e.g., strains), fiber necrosis, insufficient regeneration, and probably development of scar tissue. ${ }^{4,28,70}$ Other factors may also affect the predisposition and susceptibility to EIMD. Sex may be related to variations often seen in EIMD manifestations with women demonstrating strength decrements, DOMS, and membrane disruption of smaller magnitude ${ }^{79,80}$ probably due to a prophylactic effect of estrogens on muscle fiber membranes, calcium homeostasis, and inflammatory reaction. ${ }^{81-83}$ Whether DOMS responses are sex-dependent is less clear.

Other factors that may attenuate EIMD manifestations are regular exercise training and utilization of nutritional supplements (i.e., anti-inflammatory agents, antioxidants, and creatine supplementation). ${ }^{7,84,85}$ Since athletes have a heavy schedule, with training or sometimes competing more than once a day, finding ways to maximize or accelerate the recovery process from exercise training becomes crucial for their 
performance. Nutritional strategies, either by using dietary supplements or foods, have been proposed in the literature to encounter this challenge. It has been shown, for example, that protein supplementation, mainly through the ingestion of amino acids, has a positive effect in reducing muscle soreness following an exercise bout and accelerating functional recovery. ${ }^{86}$ Furthermore, subjects receiving food supplements such as cherry or pomegranate juice had a faster recovery in performance following an EIMD protocol. ${ }^{87-89}$ In addition, creatine supplementation has been shown to attenuate EIMD following an eccentric exercise protocol..$^{90}$ Potential mechanisms that explain the effect of creatine supplementation on EIMD include a reduction in the inflammatory response and oxidative stress and regulation in the calcium homeostasis as well as promotion of proliferation and differentiation of satellite cells. ${ }^{91}$ However, not all supplements have been proven to be effective, ${ }^{92,93}$ and further research is needed to identify foods and supplements that are effective in either preventing EIMD or speeding up the recovery process.

\section{The inflammatory response associated with EIMD}

Locally, EIMD leads to leukocyte mobilization to the injured muscle tissue. The first leukocyte subpopulation that infiltrates traumatized muscle is the neutrophils within 4-6 $\mathrm{h}$ and remains elevated during the $24 \mathrm{~h}$ postinjury. ${ }^{17,94-96}$ Macrophage infiltration into the injured muscle follows 1-14 days postinjury depending on the magnitude of the insult. ${ }^{17,95,97}$ The mission of the leukocyte subsets is to remove cellular debris such as damaged protein molecules by releasing reactive oxygen and nitrogen species during a process called respiratory burst, ${ }^{7,96,98-100}$ proteolytic enzymes, ${ }^{52}$ and by synthesizing proinflammatory cytokines such as IL-1 $\beta$, IL-6, IL-8, TNF- $\alpha$, and monocyte chemotactic protein-1 which are also expressed by muscle cells probably within the first $24 \mathrm{~h}$ after exercise. ${ }^{97,101}$ At this time, EIMD results in changes of the expression of leukocyte receptors as well as their activity thereby regulating their ability to infiltrate into the damaged tissue. ${ }^{102}$ These changes are paralleled by an upregulation of major adhesion molecules. ${ }^{22,103}$ Proinflammatory cytokines seem to start the disintegration of cellular fragments. ${ }^{104}$ A second wave of proinflammatory cytokines (e.g., IL-6 and transforming growth factor) are produced by damaged skeletal muscle several days within recovery. ${ }^{97,105,106}$ Other proinflammatory cytokines may be expressed and released by infiltrating immune cells such as IL-4 and IL-1 receptor antagonist (IL-1 ra). ${ }^{95,106}$ Removal of cellular debris may be a prerequisite for the subsequent regeneration of injured myofibers. ${ }^{107}$ Consequently, injured muscle develops an intense chemotactic action to attract immune cells that are usually detected first in the extracellular compartment (1-3 days) and then intracellularly (4-8 days). ${ }^{7,35,39,108}$ The greater the damage the greater the infiltration of immune cells in the muscle environment. ${ }^{39,108,109}$ Recent evidence suggests that this inflammatory phase may be under redox-dependent regulation through the mediation of key intracellular signaling pathways such as that of NF- $\mathrm{KB}$ and MAPK which control cytokine synthesis and immune activation. ${ }^{7}$

The acute inflammatory response following damaging exercise elevates leukocyte numbers not only within the muscle milieu but also in the circulation, suggesting that EIMD elicits a systemic inflammatory response as well. This immune response is greater following eccentric exercise protocols (i.e., eccentric dynamometry, eccentric cycling, and downhill running) than other types or modes of exercise incorporating both concentric and eccentric actions such as level running, stepping, jumping, resistance exercise training, and sport activity..$^{95,103,104,110-120}$ These differences are largely attributed to the characteristics of exercise (intensity, duration, and volume), muscle groups involved, and types of contraction that affect stress hormones at different degrees..$^{1,22,114,121-123}$ These systemic immune changes are accompanied by alterations in the circulatory levels of proinflammatory cytokines such IL- $1 \beta$ and TNF- $\alpha$, ${ }^{7,121,123,124}$ indicating that EIMD may cause cytokine secretion by cells other than muscle (e.g., immune cells). Interestingly, after extensive EIMD, IL-6, also produced by skeletal muscle, may remain elevated even after the completion of the inflammatory phase as it has been implicated in the activation of satellite cell during the regeneration phase $\mathrm{e}^{7,125,126}$ and release of anti-inflammatory molecules such as cortisol, IL-1 ra, and IL-10. ${ }^{127}$ Collectively, these results suggest that EIMD induced both local and systemic inflammatory responses as depicted by changes in immune cells and cytokines.

On the other hand, several investigations suggest that during this initial proinflammatory phase, a number of antiinflammatory molecules such as IL-10, IL-12, IL-1ra, soluble TNF- $\alpha$ receptors, and granulocyte-colony stimulating factor are secreted. ${ }^{7,110,124,128}$ Systemic levels or muscle expression of leukemia inhibitory factor (LIF), interferon (IFN)- $\gamma$, and cytokines $2,5,12,13,15$, and 17 seem to remain unaffected by EIMD.

Whether all types of exercises trigger such a response is questionable since the greatest elevations of these antiinflammatory cytokines have been seen following extreme types of exercise such as marathon running with IL-1 $\beta$, 
TNF- $\alpha$, and IL- 6 rise preceding that of TNF- $\alpha$ receptors and IL-1ra. ${ }^{129}$ Although some investigators suggested that these anti-inflammatory cytokines may be released by mobilized immune cells, ${ }^{130}$ the tissues secreting these molecules are unknown. Anti-inflammatory cytokines seem to suppress inflammation by hindering expression and activation of proinflammatory cytokines and generation of immune cells. ${ }^{131-133}$

Several studies have shown a correlation between the systemic levels of proinflammatory cytokines and CK activity and myoglobin levels (EIMD markers) in the circulation postexercise. ${ }^{134-136}$ Although this observation is important, it does not explain the exact role of cytokines in EIMDinduced inflammatory response. Furthermore, the origin of these cytokines remains obscure despite findings suggesting muscle and immune cells as their potential source of release. Paulsen et $\mathrm{al}^{8}$ believe that in vitro studies do not consider the complex interaction between various tissues and humoral agents during and after exercise. Consequently, under in vivo conditions, cytokine production and release may occur from specific cell types exposed to specific local inhibitory or stimulating molecules. ${ }^{8}$ Although human studies are valuable, tissue sampling may be problematic since muscle homogenates or immune cell extracts may include various cell types that are difficult to distinguish, and they all may contribute to cytokine production. ${ }^{8}$ Cytokine levels in the circulation are merely product of their appearance and disappearance kinetics in that compartment and explain very little with regard to the tissue of their origin. Most of these molecules are produced by damaged myofibers, and they exist only at the local environment and as such their measurement in the blood is not possible. ${ }^{137}$ Serial sampling of muscle biopsies or inhibition of specific cytokines may be more useful in elucidating their role in EIMD-induced inflammation. ${ }^{8}$ Animal studies showed that cytokine depletion or deficiency may attenuate recovery, suggesting that these molecules are important for muscle healing. ${ }^{138,139}$ This is mainly attributed to the inadequate mobilization of neutrophils and macrophages to the site of injury and/or an attenuated myogenic response. ${ }^{140-142}$ Interestingly, antioxidant supplementation attenuated the elevation of proinflammatory cytokines in days 1-3 postexercise and resulted in reduced recovery of muscle strength during the regeneration phase, suggesting that cytokines may be implicated in the recovery process. ${ }^{7}$

\section{Exercise-induced inflammation and sports performance}

EIMD and its associated inflammatory response is of paramount importance for athletes' performance for two basic reasons: 1) the rate of deterioration and recovery of performance and discomfort (DOMS) after an athletic activity is largely dependent on the magnitude of EIMD-induced inflammatory response and 2) it affects the frequency of training stimuli, that is, the time needed for optimal recovery in between practices, official events, and/or an event and a practice. A $>20 \%$ decline of the force-generating capacity of muscles exhibits a close association with the magnitude of muscle damage and its associated inflammatory response. ${ }^{56,143-145}$ Smaller reduction of muscle strength is usually not accompanied by histological evidence of EIMD. ${ }^{8}$ Paulsen et $\mathrm{al}^{8}$ suggested that strenuous isolated eccentric activity produces a greater degree of EIMD than the so-called eccentrically biased activities such as downhill running or intense-level running. Evidence indicates that the magnitude of force, the degree of lengthening, velocity of movement, and overall volume of eccentric load are probably the most important factors dictating the rate of muscle injury in response to exercise. ${ }^{146-156}$ In fact, it has been shown that EIMD induced by a football match is associated with the number of explosive types of movement that incorporate a strong eccentric component. ${ }^{57,157}$

In cases of mild performance decline, defined by Paulsen et $\mathrm{al}^{8}$ as a drop of strength by $<20 \%$, creatine kinase activity (CK) in blood remains $<1,000 \mathrm{U} / \mathrm{L}$, inflammation is limited, and recovery is usually fast (within 12-48 h) independent of

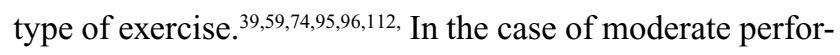
mance decline, defined by Paulsen et $\mathrm{al}^{8}$ as a drop of strength by $<20 \%-50 \%$, myofiber necrosis may be observed (mostly in high-respondents), ${ }^{39} \mathrm{CK}$ exceeds $1,000 \mathrm{U} / \mathrm{L}$, the inflammatory response is more intense with leukocyte infiltration into the injured muscle, and degradation of structural and contractile proteins may be evident and recovery is usually completed within a week..$^{22,35,39,158,159}$ In the case of severe performance decline, defined by Paulsen et $\mathrm{al}^{8}$ as a drop of strength by $>50 \%$, necrosis is usually observed in parts of the myofibers, CK may exceed $10,000 \mathrm{U} / \mathrm{L}$, soreness is quite high, muscle swelling is evident, the inflammatory response is intense and characterized by a marked accumulation of immune cells into the traumatized tissue, and recovery usually takes 1-3 weeks or even longer if strength loss is $>70 \%$. $^{24,30,39,108,109,160-166}$ In severe EIMD, increased proteolysis and muscle disruption is observed, even during early recovery, due to disturbances in calcium homeostasis. ${ }^{145,167}$ In these three scenarios, athletes may need to use different recovery strategies in order to be able to train or compete as soon as possible. Recovery treatments may be classified in four major categories: 1) pharmacological (e.g., inflammatory agents, $\mathrm{NF}-\kappa \mathrm{B}$ inhibitors, estrogen therapy, phosphodiesterase 
inhibitors, ACE inhibitors), 2) nutritional approaches and supplements (e.g., antiantioxidants, herbal remedies, alcohol ingestion, $\omega$ - 3 -fatty acids, $\beta$-hydroxy- $\beta$-methylbutyrate, protease supplementation, nucleotide supplementation, tea consumption, beetroot, caffeine, creatine, enzyme supplementation, and carbohydrate and/or protein supplementation), 3) rehabilitation and physical therapy methods (e.g., cryotherapy, heat-related treatments, compressive loading techniques, trekking poles, ultrasound and electrical current modalities, massage, hyperoxia or hypoxia, laser therapy, spa therapy, mechanomyographical feedback, vibration therapy, acupuncture, and homeopathy), and 4) exercise-related treatments (e.g., stretching and low-intensity exercise), and numerous studies and reviews have examined their effectiveness in reducing EIMD and accelerating recovery. ${ }^{168-171}$ Of those, nonsteroidal anti-inflammatory agents (depending on dosage and time of ingestion), protein supplementation, $\beta$-hydroxy- $\beta$-methylbutyrate supplementation, massage (depending on the time of administration and technique used), antioxidant supplementation, and exercise-based treatments have been shown to exert positive action. ${ }^{168-171}$ These recovery approaches aim to reduce swelling, improve blood flow, pain sensation, immune cell recruitment, and/or improve healing by activating satellite cells and anabolic factors as well as improving tendon healing. One has to remember that athletes are interested not only in the attenuation of the EIMD-related inflammatory response but also and more importantly in effective and timely performance recovery. Today, no general guidelines exist regarding the treatment of EIMD and performance recovery. Certain concerns have been raised regarding the use of anti-inflammatory agents based on reports suggesting that these products not only disrupt the inflammatory response but also hinder the adaptive response to training. ${ }^{7,172}$ However, the periods during which anti-inflammatory agents are used need to be discerned. There are training periods during which athletes need to compete and train with very high frequency (e.g., in-season training), and cessation would be beneficial. In contrast, there are periods during which athletes train aiming for long-term adaptations, and anti-inflammatory agents may disrupt both EIMD and training adaptations. In the latter case, athletes should rethink about using such recovery approaches. However, more research is needed in order to determine whether anti-inflammatory agents interfere with training adaptations.

Now it is also well-understood that athletes may be low-, moderate-, and high-respondents to EIMD, a fact that also explains the substantial interindividual variability in the responses seen following various types of exercise protocols used to induce muscle micro-injury. ${ }^{73,108,155,163,168,173-175}$ This phenomenon may be attributed to a number of factors such as age, ${ }^{154,176,177}$ preconditioning, ${ }^{178-180}$ gender, ${ }^{80,166}$ genetics, ${ }^{181,182}$ physical conditioning level, ${ }^{57,183-185}$ and joint range of motion. ${ }^{186}$ Therefore, sport practitioners should determine whether their athletes are low-, moderate-, or highrespondents, be advised to establish individual normative values for each one, and avoid absolute comparisons among athletes or generalizations. It must also be mentioned that preconditioning, a phenomenon also known as "repeated bout effect," may protect athletes from EIMD, that is, after a first session of damaging exercise, skeletal muscle tissue adapts and is less vulnerable to injury in subsequent sessions of the same type of exercise. ${ }^{153,180,187}$ In fact, it has been shown that repetition of a damaging exercise results in less EIMD, inflammation, oxidative stress, leukocyte infiltration, and strength loss. ${ }^{5,111,159,187,188}$

\section{Conclusion}

Exercise-induced inflammation is caused by EIMD which is mainly associated with eccentric type of contractions that lengthen the muscles. Under conditions of repetitive lengthening contractions, weaker sarcomeres are compromised initiating micro-tearing of myofibers that spreads out to the cellular membrane and other subsarcolemal structures as well as to extracellular matrix and connective tissue. Calcium efflux from disrupted sarcoplasmic reticulum and stretch-dependent channels activate proteolytic enzymes that contribute to muscle damage by degrading structural and contractile proteins. Although the exact mechanisms are largely unknown, EIMD triggers an inflammatory response characterized by the accumulation and infiltration of neutrophils and macrophages into the damaged tissue. The activation and mobilization of these immune cells are mediated by cytokines released by injured muscle and other cells and may be under redox regulation. Immune cells remove cellular debris and protein fragments to allow for the subsequent muscle regeneration and healing. During the inflammatory phase, muscle strength declines and DOMS develops at a rate dictated by the magnitude of the stretching stimulus. During this phase, athletic performance is compromised for hours to days depending on the magnitude of muscle damage as well as a number of other factors. There is a large interindividual variability of the responses to EIMD, and this has to be acknowledged by sport practitioners. Although a good number of studies have investigated EIMD and inflammation, the exact mechanisms responsible for the onset of DOMS remain obscure. Research needs to unravel the neural 
pathways triggering the sensation of muscle soreness, the molecular mechanisms associated with immune cell activation, and the mechanisms regulating the transition from the inflammatory phase to the healing phase. So far, there are no clear guidelines regarding recovery strategies following EIMD mainly due to inconsistencies in protocols, time of administrations, dosages, exercise protocols, and type of techniques used among studies. Future research should provide clear evidence regarding optimal treatments for effective and timely recovery of both EIMD and performance following various types of exercise training modes and methods as well as competition. New genetic and molecular methodologies will allow scientists to answer critical questions regarding the pathways regulating muscle damage and healing.

\section{Disclosure}

The authors report no conflicts of interest in this work.

\section{References}

1. Peake J, Nosaka K, Suzuki K. Characterization of inflammatory responses to eccentric exercise in humans. Exerc Immunol Rev. 2005;11:64-85.

2. Proske U, Allen TJ. Damage to skeletal muscle from eccentric exercise. Exerc Sport Sci Rev. 2005;33:98-104.

3. Fehrenbach E, Schneider ME. Trauma-induced systemic inflammatory response versus exercise-induced immunomodulatory effects. Sports Med. 2006;36:373-384.

4. Smith C, Kruger MJ, Smith RM, Myburgh KH. The inflammatory response to skeletal muscle injury: illuminating complexities. Sports Med. 2008;38:947-969.

5. Tidball JG, Villalta SA. Regulatory interactions between muscle and the immune system during muscle regeneration. Am J Physiol Regul Integr Comp Physiol. 2010;298:R1173-R1187.

6. Gomez-Cabrera MC, Borras C, Pallardo FV, Sastre J, Li LJ, Vina J. Decreasing xanthine oxidase-mediated oxidative stress prevents useful cellular adaptations to exercise in rats. J Physiol. 2005;567: 113-120.

7. Michailidis Y, Karagounis LG, Terzis G, et al. Evidence of potential redox-sensitive regulation of human skeletal muscle's performance and intracellular signaling following aseptic inflammation induced by damaging exercise. Am J Clin Nutr. 2013;98:233-245.

8. Paulsen G, Mikkelsen UR, Raastad T, Peake JM. Leucocytes, cytokines and satellite cells: what role do they play in muscle damage and regeneration following eccentric exercise? Exerc Immunol Rev. 2012;18:42-97.

9. Asmussen E. Observations on experimental muscular soreness. Acta Rheumatol Scand. 1956;2:109-116.

10. Hough T. Ergographic studies in muscular soreness. Am J PhysiolLegacy Content. 1902; 7:76-92.

11. Clarkson PM, Tremblay I. Exercise-induced muscle damage, repair, and adaptation in humans. J Appl Physiol. 1988;65:1-6.

12. Givli S. Contraction induced muscle injury: towards personalized training and recovery programs. Ann Biomed Eng. 2015;43(2):388-403.

13. Petrof BJ. The molecular basis of activity-induced muscle injury in Duchenne muscular dystrophy. Mol Cell Biochem. 2001;179:111-123.

14. Andersen SP, Sveen ML, Hansen RS, et al. Creatine kinase response to high-intensity aerobic exercise in adult-onset muscular dystrophy. Muscle Nerve. 2013;48(6):897-901.
15. Koskinen SO, Höyhtyä M, Turpeenniemi-Hujanen T, et al. Serum concentrations of collagen degrading enzymes and their inhibitors after downhill running. Scand J Med Sci Sports. 2001;11(1):9-15.

16. Buono R, Vantaggiato C, Pisa V, et al. Nitric oxide sustains long-term skeletal muscle regeneration by regulating fate of satellite cells via signaling pathways requiring Vang12 and cyclic GMP. Stem Cells. 2012;30(2):197-209.

17. Sciorati C, Buono R, Azzoni E, et al. Co-administration of ibuprofen and nitric oxide is an effective experimental therapy for muscular dystrophy, with immediate applicability to humans. Br J Pharmacol. 2010;160(6):1550-1560.

18. Nunes VA, Gozzo AJ, Cruz-Silva I, et al. Vitamin E prevents cell death induced by mild oxidative stress in chicken skeletal muscle cells. Comp Biochem Physiol C Toxicol Pharmacol. 2005;141(3):225-240.

19. Stavropoulos-Kalinoglou A, Metsios GS, Koutedakis Y, et al. Redefining overweight and obesity in rheumatoid arthritis patients. Ann Rheum Dis. 2007;66(10):1316-1321.

20. Joosten LA, Abdollahi-Roodsaz S, Dinarello CA, O’Neill L, Netea MG. Toll-like receptors and chronic inflammation in rheumatic diseases: new developments. Nat Rev Rheumatol. 2016;12(6):344-357.

21. Newham D, Jones D, Edwards R. Large delayed plasma creatine kinase changes after stepping exercise. Muscle Nerve. 1983;6:380-385.

22. Mohr M, Draganidis D, Chatzinikolaou A, et al. Muscle damage, inflammatory, immune and performance responses to three football games in one week in competitive male players. Eur J Appl Physiol. 2016;116(1):179-193.

23. Friden J, Sjostrom M, Ekblom B. A morphological study of delayed muscle soreness. Experientia. 1981;37:506-507.

24. Raastad T, Owe SG, Paulsen G, et al. Changes in calpain activity, muscle structure, and function after eccentric exercise. Med Sci Sports Exerc. 2010;42:86-95.

25. Hamer P, McGeachie J, Davies M, Grounds M. Evans blue dye as an in vivo marker of myofibre damage: optimising parameters for detecting initial myofibre membrane permeability. J Anat. 2002;200: 69-79.

26. Crameri RM, Langberg H, Magnusson $P$, et al. Changes in satellite cells in human skeletal muscle after a single bout of high intensity exercise. J Physiol. 2004;558:333-340.

27. Stauber WT, Clarkson PM, Fritz VK, Evans WJ. Extracellular matrix disruption and pain after eccentric muscle action. J Appl Physiol. 1990;69:868-874.

28. Allen DG, Gervasio OL, Yeung EW, Whitehead NP. Calcium and the damage pathways in muscular dystrophy. Can J Physiol Pharmacol. 2010;88:83-91.

29. Whitehead NP, Pham C, Gervasio OL, Allen DG. N-Acetylcysteine ameliorates skeletal muscle pathophysiology in mdx mice. J Physiol. 2008;586:2003-2014.

30. Lauritzen F, Paulsen G, Raastad T, Bergersen LH, Owe SG. Gross ultrastructural changes and necrotic fiber segments in elbow flexor muscles after maximal voluntary eccentric action in humans. J Appl Physiol. 2009;107:1923-1934.

31. Yu JG, Liu JX, Carlsson L, Thornell LE, Stal PS. Re-evaluation of sarcolemma injury and muscle swelling in human skeletal muscles after eccentric exercise. PLoS One. 2013;8:e62056.

32. Crameri RM, Aagaard P, Qvortrup K, Langberg H, Olesen J, Kjaer M. Myofibre damage in human skeletal muscle: effects of electrical stimulation versus voluntary contraction. J Physiol. 2007;583:365-380.

33. Newham DJ, McPhail G, Mills KR, Edwards RH. Ultrastructural changes after concentric and eccentric contractions of human muscle. J Neurol Sci. 1983;61:109-122.

34. Lieber RL, Thornell LE, Friden J. Muscle cytoskeletal disruption occurs within the first $15 \mathrm{~min}$ of cyclic eccentric contraction. $J$ Appl Physiol. 1996;80:278-284.

35. Beaton LJ, Tarnopolsky MA, Phillips SM. Contraction-induced muscle damage in humans following calcium channel blocker administration. J Physiol. 2002;544:849-859. 
36. Lovering RM, De Deyne PG. Contractile function, sarcolemma integrity, and the loss of dystrophin after skeletal muscle eccentric contraction-induced injury. Am J Physiol Cell Physiol. 2004;286:C230-C238.

37. Trump BF, Laiho KA, Mergner WJ, Arstila AU. Studies on the subcellular pathophysiology of acute lethal cell injury. Beitr Pathol. 1974;152:243-271.

38. Paulsen G, Egner IM, Drange M, et al. A COX-2 inhibitor reduces muscle soreness, but does not influence recovery and adaptation after eccentric exercise. Scand J Med Sci Sports. 2010;20:e195-e207.

39. Cavassani KA, Ishii M, Wen H, et al. TLR3 is an endogenous sensor of tissue necrosis during acute inflammatory events. J Exp Med. 2008;205:2609-2621.

40. Mathes AL, Lafyatis R. Role for Toll-like receptor 3 in muscle regeneration after cardiotoxin injury. Muscle Nerve. 2011;43:733-740.

41. Jarvinen TA, Jarvinen TL, Kaariainen M, Kalimo H, Jarvinen M. Muscle injuries: biology and treatment. Am J Sports Med. 2005;33: 745-764.

42. Lieber RL, Friden J. Mechanisms of muscle injury gleaned from animal models. Am J Phys Med Rehabil. 2002;81:S70-S79.

43. Stauber WT, Smith CA. Cellular responses in exertion-induced skeletal muscle injury. Mol Cell Biochem. 1998;179:189-196.

44. Yu JG, Carlsson L, Thornell LE. Evidence for myofibril remodelling as opposed to myofibril damage in human muscles with DOMS: an ultrastructural and immunoelectron microscopic study. Histochem Cell Biol. 2004;121:219-227.

45. Malm C, Sjodin TLB, Sjoberg B, et al. Leukocytes, cytokines, growth factors and hormones in human skeletal muscle and blood after uphill or downhill running. $J$ Physiol. 2004;556:983-1000.

46. Hyldahl RD, Hubal MJ. Lengthening our perspective: morphological, cellular, and molecular responses to eccentric exercise. Muscle Nerve. 2014;49:155-170.

47. Jamurtas AZ, Theocharis V, Tofas T, et al. Comparison between leg and arm eccentric exercises of the same relative intensity on indices of muscle damage. Eur J Appl Physiol. 2005;95(2-3):179-185.

48. Kjaer M. Role of extracellular matrix in adaptation of tendon and skeletal muscle to mechanical loading. Physiol Rev. 2004;84:649-698.

49. Heinemeier KM, Olesen JL, Haddad F, et al. Expression of collagen and related growth factors in rat tendon and skeletal muscle in response to specific contraction types. J Physiol. 2007;582:1303-1316.

50. Tofas T, Jamurtas AZ, Fatouros I, et al. The effects of plyometric exercise on muscle performance, muscle damage and collagen breakdown. J Strength Cond Res. 2008;22(2):490-496.

51. Husmann I, Soulet L, Gautron J, Martelly I, Barritault D. Growth factors in skeletal muscle regeneration. Cytokine Growth Factor Rev 1996;7:249-258.

52. Tidball J. Inflammatory processes in muscle injury and repair. Am J Physiol. 2005;288:R345-R353.

53. Hyldahl RD, Xin L, Hubal MJ, Moeckel-Cole S, Chipkin S, Clarkson PM. Activation of nuclear factor-fkappagB following muscle eccentric contractions in humans is localized primarily to skeletal muscleresiding pericytes. FASEB J. 2011;25:2956-2966.

54. Hyldahl RD, Schwartz LM, Clarkson PM. NF-KB activity functions in primary pericytes in a cell- and non-cell-autonomous manner to affect myotube formation. Muscle Nerve. 2013;47:522-531.

55. Li H, Malhotra S, Kumar A. Nuclear factor-kappa B signalling in skeletal muscle atrophy. J Mol Med. 2008;86:1113-1126.

56. Clarkson PM, Dedrick ME. Exercise-induced muscle damage, repair, and adaptation in old and young subjects. J Gerontol. 1988;43: M91-M96.

57. Draganidis D, Chatzinikolaou A, Avloniti A, et al. Flexor and extensor strength after a football match. PLoS One. 2015;10(6):e0128072.

58. Clarkson PM, Hubal MJ. Exercise-induced muscle damage in humans. Am J Phys Med Rehabil. 2002;81:S52-S69.

59. Chatzinikolaou A, Christoforidis C, Avloniti A, et al. A microcycle of inflammation following a team-handball game. J Strength Cond Res. 2013;28(7):1981-1994.
60. Morgan DL. New insights into the behavior of muscle during active lengthening. Biophys J. 1990;57:209-221.

61. Komazaki S, Ito K, Takeshima H, Nakamura H. Deficiency of triad formation in developing skeletal muscle cells lacking junctophilin type 1. FEBS Lett. 2002;524:225-229.

62. Corona BT, Balog EM, Doyle JA, Rupp JC, Luke RC, Ingalls CP. Junctophilin damage contributes to early strength deficits and EC coupling failure after eccentric contractions. Am J Physiol Cell Physiol. 2010;298:C365-C376.

63. Balnave CD, Allen DG. Intracellular calcium and force in single mouse muscle fibres following repeated contractions with stretch. J Physiol. 1995;488:25-36.

64. Balnave CD, Davey DF, Allen DG. Distribution of sarcomere length and intracellular calcium in mouse skeletal muscle following stretchinduced injury. J Physiol. 1997;502:649-659.

65. Warren GL, Ingalls CP, Lowe DA, Armstrong RB. What mechanisms contribute to the strength loss that occurs during and in the recovery from skeletal muscle injury? J Orthop Sports Phys Ther. 2002;32:58-64.

66. Murphy RM, Dutka TL, Horvath D, Bell JR, Delbridge LM, Lamb GD Ca21-dependent proteolysis of junctophilin-1 and junctophilin-2 in skeletal and cardiac muscle. J Physiol. 2013;591:719-729.

67. Chan S, Head SI, Morley JW. Branched fibers in dystrophic mdx muscle are associated with a loss of force following lengthening contractions. Am J Physiol Cell Physiol. 2007;293:C985-C992.

68. Whitehead N, Streamer M, Lusambili L, Sachs F, Allen D. Streptomycin reduces stretch-induced membrane permeability in muscles from mdx mice. Neuromuscul Disord. 2006;16:845-854.

69. Yeung EW, Whitehead NP, Suchyna TM, Gottlieb PA, Sachs F, Allen DG. Effects of stretch-activated channel blockers on [Ca21]i and muscle damage in the mdx mouse. J Physiol. 2005;562:367-380.

70. Butterfield TA, Best TM. Stretch-activated ion channel blockade attenuates adaptations to eccentric exercise. Med Sci Sports Exerc. 2009;41:351-356.

71. Clarkson PM, Devaney JM, Gordish-Dressman H, et al. ACTN3 genotype is associated with increases in muscle strength in response to resistance training in women. J Appl Physiol. 2005;99:154-163.

72. Seto JT, Lek M, Quinlan KGR, et al. Deficiency of falphag-actinin-3 is associated with increased susceptibility to contraction-induced damage and skeletal muscle remodeling. Hum Mol Genet. 2011;20:2914-2927.

73. Clarkson PM, Nosaka K, Braun B. Muscle function after exerciseinduced muscle damage and rapid adaptation. Med Sci Sports Exerc. 1992;24:512-520.

74. Chatzinikolaou A, Draganidis D, Avloniti A, et al. The microcycle of inflammation and performance changes after a basketball match. J Sports Sci. 2013;32(9):870-882.

75. Armstrong RB. Mechanisms of exercise-induced delayed onset muscular soreness: a brief review. Med Sci Sports Exerc. 1984;16:529-538.

76. Radak Z, Naito H, Taylor AW, Goto S. Nitric oxide: is it the cause of muscle soreness? Nitric Oxide. 2012;26(2):89-94.

77. Murase S, Terazawa E, Queme F, et al. Bradykinin and nerve growth factor play pivotal roles in muscular mechanical hyperalgesia after exercise (delayed-onset muscle soreness). J Neurosci. 2010;30:3752-3761.

78. Nie H, Madeleine P, Arendt-Nielsen L, Graven-Nielsen T. Temporal summation of pressure pain during muscle hyperalgesia evoked by nerve growth factor and eccentric contractions. Eur J Pain. 2009;13:704-710.

79. Sewright K, Hubal M, Kearns A, Holbrook M, Clarkson P. Sex differences in response to maximal eccentric exercise. Med Sci Sports Exerc. 2008;40:242-251.

80. Clarkson P, Hubal M. Are women less susceptible to exercise induced muscle damage? Curr Opin Clin Nutr Metab Care. 2001;4:527-531.

81. Enns D, Iqbal S, Tiidus P. Oestrogen receptors mediate oestrogeninduced increases in post-exercise rat skeletal muscle satellite cells. Acta Physiol (Oxf). 2008;194:81-93. 
82. Iqbal S, Thomas A, Bunyan K, Tiidus P. Progesterone and estrogen influence postexercise leukocyte infiltration in overiectomized female rats. Appl Physiol Nutr Metab. 2008;33:1207-1212.

83. Sonobe T, Inagaki T, Sudo M, Poole DC, Kano Y. Sex differences in intracellular $\mathrm{Ca}(21)$ accumulation following eccentric contractions of rat skeletal muscle in vivo. Am J Physiol Regul Integr Comp Physiol. 2010;299:R1006-R1012.

84. McGinley C, Shafat A, Donnelly A. Does antioxidant vitamin supplementation protect against muscle damage? Sports Med. 2009;39:1011-1032.

85. Cooke M, Rybalka E, Williams A, Cribb P, Hayes A. Creatine supplementation enhances muscle force recovery after eccentrically induced muscle damage in healthy individuals. Int Soc Sports Nutr. 2009;6:13.

86. Howatson G, Hoad M, Goodall S, Tallent J, Bell PG, French DN. Exercise-induced muscle damage is reduced in resistance-trained males by branched chain amino acids: a randomized, double-blind, placebo controlled study. J Int Soc Sports Nutr. 2012;9:20.

87. Bowtell JL, Sumners DP, Dyer A, Fox P, Mileva KN. Montmorency cherry juice reduces muscle damage caused by intensive strength exercise. Med Sci Sports Exerc. 2011;43:1544-1551.

88. Trombold JR, Reinfeld AS, Casler JR, Coyle EF. The effect of pomegranate juice supplementation on strength and soreness after eccentric exercise. J Strength Cond Res. 2011;25:1782-1788.

89. Connolly DJ, McHugh MP, Padilla-Zakour OI. Efficacy of a tart cherry juice blend in preventing the symptoms of muscle damage. Br J Sports Med. 2006;40:679-683.

90. Rosene J, Matthews T, Ryan C, et al. Short and longer-term effects of creatine supplementation on exercise induced muscle damage. J Sports Sci Med. 2009;8:89-96.

91. Kim J, Lee J, Kim S, Yoon D, Kim J, Sung DJ. Role of creatine supplementation in exercise-induced muscle damage: a mini review. J Exerc Rehab. 2015;11(5):244-250.

92. Sousa M, Teixeira VH, Soares J. Dietary strategies to recover from exercise-induced muscle damage. Int J Food Sci Nutr. 2014;65(2):151-163.

93. Theodorou AA, Nikolaidis MG, Paschalis V, et al. No effect of antioxidant supplementation on muscle performance and blood redox status adaptations to eccentric training. Am J Clin Nutr. 2011;93:1373-1383.

94. MacIntyre DL, Reid WD, Lyster DM, Szasz IJ, McKenzie DC. Presence of WBC, decreased strength, and delayed soreness in muscle after eccentric exercise. J Appl Physiol. 1996;80:1006-1013.

95. Malm C, Nyberg P, Engstrom M, et al. Immunological changes in human skeletal muscle and blood after eccentric exercise and multiple biopsies. J Physiol. 2000;529:243-262.

96. Raastad T, Risoy BA, Benestad HB, Fjeld JG, Hallen J. Temporal relation between leukocyte accumulation in muscles and halted recovery 10-20 h after strength exercise. J Appl Physiol. 2003;95: 2503-2509.

97. Hamada K, Vannier E, Sacheck JM, Witsell AL, Roubenoff R. Senescence of human skeletal muscle impairs the local inflammatory cytokine response to acute eccentric exercise. FASEB J. 2005;19:264-266.

98. Cannon JG, St Pierre BA. Cytokines in exertion-induced skeletal muscle injury. Mol Cell Biochem. 1998;179:159-167.

99. Nguyen HX, Tidball JG. Null mutation of gp91phox reduces muscle membrane lysis during muscle inflammation in mice. $J$ Physiol. 2003;553:833-841.

100. Peake JM. Exercise-induced alterations in neutrophil degranulation and respiratory burst activity: possible mechanisms of action. Exerc Immunol Rev. 2002;8:49-100.

101. Fielding R, Manfredi T, Ding W, Fiatarone M, Evans W, Cannon J. Acute phase response in exercise III. Neutrophil and IL-beta accumulation in skeletal muscle. Am J Physiol. 1993;265:R166-R172.

102. Arnaout MA. Structure and function of the leukocyte adhesion molecules CD11/CD18. Blood. 1990;75:1037-1050.

103. Petridou A, Chatzinikolaou A, Fatouros IG, et al. Resistance exercise does not affect the serum concentrations of cell adhesion molecules. Br J Sports Med. 2007;41:76-79.
104. Cannon J, Orencole S, Fielding R, et al. Acute phase response in exercise: interaction of age and vitamin $\mathrm{E}$ on neutrophils and muscle enzyme release. Am J Physiol. 1990;259:R1214-R1219.

105. Barbas I, Fatouros IG, Douroudos II, et al. Physiological and performance adaptations of elite Greco-Roman wrestlers during a one-day tournament. Eur J Appl Physiol. 2011;111(7):1421-1436.

106. Nieman DC, Davis JM, Henson DA, et al. Carbohydrate ingestion influences skeletal muscle cytokine mRNA and plasma cytokine levels after a 3-h run. J Appl Physiol. 2003;94:1917-1925.

107. Trappe TA, White F, Lambert CP, Cesar D, Hellerstein M, Evans WJ. Effect of ibuprofen and acetaminophen on postexercise muscle protein synthesis. Am J Physiol Endocrinol Metab. 2002;282:E551-556.

108. Paulsen G, Crameri R, Benestad HB, et al. Time course of leukocyte accumulation in human muscle after eccentric exercise. Med Sci Sports Exerc. 2010;42:75-85.

109. Round JM, Jones DA, Cambridge G. Cellular infiltrates in human skeletal muscle: exercise induced damage as a model for inflammatory muscle disease? J Neurol Sci. 1987;82:1-11.

110. Peake JM, Suzuki K, Wilson G, et al. Exercise-induced muscle damage, plasma cytokines and markers of neutrophil activation. Med Sci Sports Exerc. 2005;37:737-745.

111. Pizza FX, Davis BH, Henrickson SD, et al. Adaptation to eccentric exercise: effect on CD64 and CD11b/CD18 expression. JAppl Physiol. 1996;80:47-55.

112. Draganidis D, Chatzinikolaou A, Jamurtas AZ, et al. The time-frame of acute resistance exercise effects on football skill performance: the impact of exercise intensity. J Sport Sci. 2013;31(7):714-722.

113. Malm C, Lenkei R, Sjodin B. Effects of eccentric exercise on the immune system in men. J Appl Physiol. 1999;86:461-468.

114. Fatouros IG, Chatzinikolaou A, Paltoglou G, et al. Stress of acute resistance exercise results in catecholaminergic 1 rather than hypothalamicpituitary-adrenal axis stimulation. Stress. 2010;13(6):461-468.

115. Fatouros IG, Chatzinikolaou A, Douroudos II, et al. Time-course of changes in oxidative stress and antioxidant status responses following a soccer game. J Strength Cond Res. 2010;24(12):3278-3286.

116. Theodorou AA, Nikolaidis MG, Paschalis V, et al. Comparison between G6PD-deficient and normal individuals after eccentric exercise. Med Sci Sports Exerc. 2010;42(6):1113-1121.

117. Chatzinikolaou A, Fatouros IG, Gourgoulis V, et al. Time course of responses in performance and inflammatory responses following acute plyometric exercise. J Strength Cond Res. 2010;24(5):1389-1398.

118. Ispirlidis I, Fatouros IG, Jamurtas AZ, et al. Time-course of changes in performance and inflammatory responses following a football game. Clin J Sports Med. 2008;18(5):423-431.

119. Margonis K, Fatouros IG, Jamourtas AZ, et al. Oxidative stress biomarkers responses to physical overtraining: implications for diagnosis. Free Rad Biol Med. 2007;43:901-910.

120. Michailidis Y, Jamurtas AZ, Nikolaidis MG, et al. Sampling time is crucial for measurement of exercise-induced oxidative stress markers. Med Sci Sports Exerc. 2007;39(7):1107-1113.

121. Brenner IK, Natale VM, Vasiliou P, Moldoveanu AI, Shek PN, Shephard RJ. Impact of three different types of exercise on components of the inflammatory response. Eur J Appl Physiol. 1999;80: 452-460.

122. Suzuki K, Nakaji S, Yamada M, Totsuka M, Sato K, Sugawara K. Systemic inflammatory response to exhaustive exercise. Cytokine kinetics. Exerc Immunol Rev. 2002;8:6-48.

123. Toft AD, Jensen LB, Bruunsgaard H, et al. Cytokine response to eccentric exercise in young and elderly humans. Am J Physiol. 2002;283:C289-C295.

124. Smith L, Anwar A, Fragen M, Rananto C, Johnson R, Holbert D. Cytokines and cell adhesion molecules associated with high-intensity eccentric exercise. Eur J Appl Physiol. 2000;82:61-67.

125. Phillips T, Childs AC, Dreon DM, Phinney S, Leeuwenburgh C. A dietary supplement attenuates IL-6 and CRP after eccentric exercise in untrained males. Med Sci Sports Exerc. 2003;35:2032-2037. 
126. Childs A, Jacobs C, Kaminski T, Halliwell B, Leeuwenburgh C. Supplementation with vitamin $\mathrm{C}$ and $\mathrm{N}$-acetyl-cysteine increases oxidative stress in humans after an acute muscle injury induced by eccentric exercise. Free Radic Biol Med. 2001;31:745-753.

127. Petersen AM, Pedersen BK. The anti-inflammatory effect of exercise. J Appl Physiol. 2005;98:1154-1162.

128. Wright CR, Della-Gatta PA, Fatouros IG, et al. The role and regulation of G-CSF and its receptor in skeletal muscle inflammation. $J$ Interf Cytokine Res. 2015;35(9):710-719.

129. Ostrowski K, Rohde T, Asp S, Schjerling P, Pedersen BK. Pro- and anti-inflammatory cytokine balance in strenuous exercise in humans. J Physiol. 1999;515:287-291.

130. Steensberg A, Fischer CP, Keller C, Moller K, Pedersen BK. IL-6 enhances plasma IL-1 ra, IL-10, and cortisol in humans. Am J Physiol. 2003;285:E433-E437.

131. Bogdan C, Paik J, Vodovotz Y, Nathan C. Contrasting mechanisms for suppression of macrophage cytokine release by transforming growth factor-beta and interleukin-10. J Biol Chem. 1992;267:23301-23308.

132. Wang P, Wu P, Siegel MI, Egan RW, Billah MM. IL-10 inhibits transcription of cytokine genes in human peripheral blood mononuclear cells. J Immunol. 1994;153:811-816.

133. Dinarello CA. The role of the interleukin-1-receptor antagonist in blocking inflammation mediated by interleukin-1. $N$ Engl $\mathrm{J}$ Med. 2000;343:732-734

134. Bruunsgaard H, Galbo H, Halkjaer-Kristensen J, Johansen TL, MacLean DA, Pedersen BK. Exercise-induced increase in serum interleukin-6 in humans is related to muscle damage. J Physiol. 499 1997;(Pt 3):833-841.

135. Hirose L, Nosaka K, Newton M, et al. Changes in inflammatory mediators following eccentric exercise of the elbow flexors. Exerc Immunol Rev. 2004;10:75-90.

136. Nieman DC, Dumke CL, Henson DA, McAnulty SR, Gross SJ, Lind RH. Muscle damage is linked to cytokine changes following a 160-km race. Brain Behav Immun. 2005;19:398-403.

137. Steensberg A, Keller C, Starkie RL, Osada T, Febbraio MA, Pedersen BK. IL-6 and TNF-alpha expression in, and release from, contracting human skeletal muscle. Am J Physiol Endocrinol Metab. 2002;283:E1272-E1278.

138. Warren GL, O'farrell L, Summan M, et al. Role of CC chemokines in skeletal muscle functional restoration after injury. Am J Physiol Cell Physiol. 2004;286:C1031-C1036.

139. Shireman PK, Contreras-Shannon V, Ochoa O, Karia BP, Michalek JE, McManus LM. MCP-1 deficiency causes altered inflammation with impaired skeletal muscle regeneration. J Leukoc Biol. 2007;81:775-785.

140. Warren GL, Hulderman T, Jensen N, et al. Physiological role of tumor necrosis factor alpha in traumatic muscle injury. FASEB $J$. 2002;16:1630-1632.

141. Serrano AL, Baeza-Raja B, Perdiguero E, Jardi M, Munoz-Canoves P. Interleukin-6 is an essential regulator of satellite cell-mediated skeletal muscle hypertrophy. Cell Metab. 2008;7:33-44.

142. Baeza-Raja B, Munoz-Canoves P. p38 MAPK-induced nuclear factorkappaB activity is required for skeletal muscle differentiation: role of interleukin-6. Mol Biol Cell. 2004;15:2013-2026.

143. Byrne C, Twist C, Eston R. Neuromuscular function after exerciseinduced muscle damage: theoretical and applied implications. Sports Med. 2004;34:49-69.

144. Friden J, Lieber RL. Eccentric exercise-induced injuries to contractile and cytoskeletal muscle fibre components. Acta Physiol Scand. 2001;171:321-326.

145. Proske U, Morgan DL. Muscle damage from eccentric exercise: mechanism, mechanical signs, adaptation and clinical applications. J Physiol. 2001;537:333-345.

146. Brooks SV, Zerba E, Faulkner JA. Injury to muscle fibres after single stretches of passive and maximally stimulated muscles in mice. J Physiol. 1995;488(Pt 2):459-469.
147. Gregory JE, Morgan DL, Allen TJ, Proske U. The shift in muscle's length-tension relation after exercise attributed to increased series compliance. Eur J Appl Physiol. 2007;99:431-441.

148. Lieber RL, Friden J. Muscle damage is not a function of muscle force but active muscle strain. J Appl Physiol. 1993;74:520-526.

149. Lieber RL, Woodburn TM, Friden J. Muscle damage induced by eccentric contractions of 25\% strain. J Appl Physiol. 1991;70:2498-2507.

150. Talbot JA, Morgan DL. Quantitative analysis of sarcomere nonuniformities in active muscle following a stretch. J Muscle Res Cell Motil. 1996;17:261-268.

151. Talbot JA, Morgan DL. The effects of stretch parameters on eccentric exercise-induced damage to toad skeletal muscle. J Muscle Res Cell Motil. 1998;19:237-245.

152. Nosaka K, Newton M, Sacco P. Delayed-onset muscle soreness does not reflect the magnitude of eccentric exercise-induced muscle damage. Scand J Med Sci Sports. 2002;12:337-346.

153. Nosaka K, Sakamoto K, Newton M, Sacco P. The repeated bout effect of reduced-load eccentric exercise on elbow flexor muscle damage. Eur J Appl Physiol. 2001;85:34-40.

154. Chapman D, Newton M, Sacco P, Nosaka K. Greater muscle damage induced by fast versus slow velocity eccentric exercise. Int $J$ Sports Med. 2006;27:591-598.

155. Chapman DW, Newton M, McGuigan M, Nosaka K. Effect of lengthening contraction velocity on muscle damage of the elbow flexors. Med Sci Sports Exerc. 2008;40:926-933.

156. Paddon-Jones D, Keech A, Lonergan A, Abernethy P. Differential expression of muscle damage in humans following acute fast and slow velocity eccentric exercise. J Sci Med Sport. 2005;8:255-263.

157. Nedelec M, McCall A, Carling C, Legall F, Berthoin S, Dupont G. Recovery in soccer: part I-post-match fatigue and time course of recovery. Sports Med. 2012;42(12):997-1015.

158. Hubal MJ, Chen TC, Thompson PD, Clarkson PM. Inflammatory gene changes associated with the repeated-bout effect. Am J Physiol Regul Integr Comp Physiol. 2008;294:R1628-R1637.

159. Stupka N, Tarnopolsky MA, Yardley NJ, Phillips SM. Cellular adaptation to repeated eccentric exercise-induced muscle damage. $J$ Appl Physiol. 2001;91:1669-1678.

160. Friden J, Lieber RL. Serum creatine kinase level is a poor predictor of muscle function after injury. Scand J Med Sci Sports. 2001;11:126-127.

161. Manfredi TG, Fielding RA, O'Reilly KP, Meredith CN, Lee HY, Evans WJ. Plasma creatine kinase activity and exercise-induced muscle damage in older men. Med Sci Sports Exerc. 1991;23:1028-1034.

162. Sorichter S, Puschendorf B, Mair J. Skeletal muscle injury induced by eccentric muscle action: muscle proteins as markers of muscle fiber injury. Exerc Immunol Rev. 1999;5:5-21.

163. Nosaka K, Clarkson PM. Variability in serum creatine kinase response after eccentric exercise of the elbow flexors. Int J Sports Med. 1996; 17:120-127.

164. Jones DA, Newham DJ, Round JM, Tolfree SE. Experimental human muscle damage: morphological changes in relation to other indices of damage. J Physiol. 1986;375:435-448.

165. Clarkson PM, Newham DJ. Associations between muscle soreness, damage, and fatigue. Adv Exp Med Biol. 1995;384:457-469.

166. Sayers SP, Clarkson PM. Force recovery after eccentric exercise in males and females. Eur J Appl Physiol. 2001;84:122-126.

167. Foley JM, Jayaraman RC, Prior BM, Pivarnik JM, Meyer RA. MR measurements of muscle damage and adaptation after eccentric exercise. J Appl Physiol. 1999;87:2311-2318.

168. Bishop PA, Jones E, Woods AK. Recovery from training: a brief review. J Strength Cond Res. 2008;22(3):1015-1024.

169. Howatson F, van Someren KA. The prevention and treatment of exercise-induced muscle damage. Sports Med. 2008;38(6):483-503.

170. Connolly DAJ, Sayers SP, McHugh MP. Treatment and prevention of delayed onset muscle soreness. J Strength Cond Res. 2003;17(1): 197-208. 
171. Cheung K, Hume PA, Maxwell L. Delayed onset muscle soreness treatment strategies and performance factors. Sports Med. 2003;33(2):145-164.

172. Gomez-Cabrera MC, Domenech E, Romagnoli M, et al. Oral administration of vitamin $\mathrm{C}$ decreases muscle mitochondrial biogenesis and hampers training-induced adaptations in endurance performance. Am J Clin Nutr. 2008;87:142-149.

173. Chen TC. Variability in muscle damage after eccentric exercise and the repeated bout effect. Res Q Exerc Sport. 2006;77:362-371.

174. Hubal MJ, Rubinstein SR, Clarkson PM. Mechanisms of variability in strength loss after muscle-lengthening actions. Med Sci Sports Exerc. 2007;39:461-468.

175. Sayers SP, Knight CA, Clarkson PM. Neuromuscular variables affecting the magnitude of force loss after eccentric exercise. J Sports Sci. 2003;21:403-410.

176. Lavender AP, Nosaka K. Responses of old men to repeated bouts of eccentric exercise of the elbow flexors in comparison with young men. Eur J Appl Physiol. 2006;97:619-626.

177. Zalavras A, Fatouros IG, Deli CK, et al. Age-related responses in circulating markers of redox status in healthy adolescents and adults during the course of a training macrocycle. Oxid Med Cell Longev. 2015; article ID 283921.

178. Nosaka K, Sakamoto K, Newton M, Sacco P. How long does the protective effect on eccentric exercise-induced muscle damage last? Med Sci Sports Exerc. 2001;33:1490-1495.

179. McHugh MP. Recent advances in the understanding of the repeated bout effect: the protective effect against muscle damage from a single bout of eccentric exercise. Scand J Med Sci Sports. 2003;13:88-97.
180. Jamurtas AZ, Fatouros IG, Buckenmeyer PJ, et al. Effects of plyometric exercise on muscle soreness and creatine kinase levels and its comparison to eccentric and concentric exercise. J Strength Cond Res. 2000;14(1):68-74.

181. Yamin C, Duarte JA, Oliveira JM, et al. IL6 (-174) and TNFA (-308) promoter polymorphisms are associated with systemic creatine kinase response to eccentric exercise. Eur J Appl Physiol. 2008;104: 579-586.

182. Hubal MJ, Devaney JM, Hoffman EP, et al. CCL2 and CCR2 polymorphisms are associated with markers of exercise-induced skeletal muscle damage. J Appl Physiol. 2010;108:1651-1658.

183. Appell HJ, Soares JM, Duarte JA. Exercise, muscle damage and fatigue. Sports Med. 1992;13:108-115.

184. Falvo MJ, Bloomer RJ. Review of exercise-induced muscle injury: relevance for athletic populations. Res Sports Med. 2006;14:65-82.

185. Gibala MJ, Interisano SA, Tarnopolsky MA, et al. Myofibrillar disruption following acute concentric and eccentric resistance exercise in strength-trained men. Can J Physiol Pharmacol. 2000;78: 656-661.

186. Chen CH, Nosaka K, Chen HL, Lin MJ, Tseng KW, Chen TC. Effects of flexibility training on eccentric exercise-induced muscle damage. Med Sci Sports Exerc. 2011;43(3):491-500.

187. Nikolaidis MG, Paschalis V, Giakas G, et al. Decreased blood oxidative stress after repeated eccentric exercise. Med Sci Sports Exerc. 2007;39(7):1080-1089.

188. Pizza FX, Baylies H, Mitchell JB. Adaptation to eccentric exercise: neutrophils and E-selectin during early recovery. Can J Appl Physiol. 2001;26:245-253.
Journal of Inflammation Research

\section{Publish your work in this journal}

The Journal of Inflammation Research is an international, peer-reviewed open access journal that welcomes laboratory and clinical findings on the molecular basis, cell biology and pharmacology of inflammation including original research, reviews, symposium reports, hypothesis formation and commentaries on: acute/chronic inflammation; mediators of
Dovepress

inflammation; cellular processes; molecular mechanisms; pharmacology and novel anti-inflammatory drugs; clinical conditions involving inflammation. The manuscript management system is completely online and includes a very quick and fair peer-review system. Visit http://www.dove press.com/testimonials.php to read real quotes from published authors. 